GA-A24480

\title{
THERMAL STUDY OF THE DIII-D MACHINE HEAT REMOVAL CAPACITY
}

\author{
by \\ H. YIP, P.M. ANDERSON, K.L. HOLTROP, \\ and S. HARRISON
}




\section{DISCLAIMER}

This report was prepared as an account of work sponsored by an agency of the United States Government. Neither the United States Government nor any agency thereof, nor any of their employees, makes any warranty, express or implied, or assumes any legal liability or responsibility for the accuracy, completeness, or usefulness of any information, apparatus, product, or process disclosed, or represents that its use would not infringe privately owned rights. Reference herein to any specific commercial product, process, or service by trade name, trademark, manufacturer, or otherwise, does not necessarily constitute or imply its endorsement, recommendation, or favoring by the United States Government or any agency thereof. The views and opinions of authors expressed herein do not necessarily state or reflect those of the United States Government or any agency thereof. 


\title{
THERMAL STUDY OF THE DIII-D MACHINE HEAT REMOVAL CAPACITY
}

\author{
by \\ H. YIP, P.M. ANDERSON, K.L. HOLTROP, \\ and S. HARRISON
}

This is a preprint of a paper presented at the 20th IEEE/NPSS Symposium on Fusion Engineering, San Diego, California, October 14-17, 2003 and to be published in Fusion Science and Technology.

\author{
Work supported by \\ the U.S. Department of Energy \\ under Contract No. DE-AC03-99ER54463
}




\title{
Thermal Study of the DIII-D Machine Heat Removal Capacity
}

\author{
H. Yip, P.M. Anderson, K.L. Holtrop, S. Harrison \\ General Atomics, PO Box 85608, San Diego, CA 92186-5608 \\ *Phone (858) 455-2455, Fax (858) 455-4190, yiphh@ @usion.gat.com
}

\begin{abstract}
With each plasma shot, the DIII-D tokamak dissipates 0.5 to $1.0 \mathrm{GJ}$ of energy. Plasma shots may occur as frequently as every ten minutes, and the energy is removed in the form of heat by a cooling water system. To remove heat from the machine, cooling water circulates through each major heat source. These sources include the power supplies, motor/generator, rf current drives, neutral beam power supplies, magnetic field coils, and vacuum vessel. The cooling water system consists of isolated primary and secondary cooling loops separated by intermediate heat exchangers. As future DIII-D plans include operation during summer months and longer pulse duration, the cooling system's overall heat removal capacity and performance efficiency must be assessed. Temperature and flow data from around the DIII-D facility are collected by a programmable logic controller (PLC); the data are used to analyze the heat generating sources, the heat transfer rate to intermediate heat exchangers, and the ultimate heat rejection to the environment via the cooling towers. A comparison of the original DIII-D machine design versus the actual performance determines the margin of heat removal capacity. Projections of the heat removal rate for various longer plasma shots are made. Improvements in design and/or operational procedure will be necessary to attain the desired pulse duration.
\end{abstract}

\section{INTRODUCTION}

This paper will describe the DIII-D cooling water system and discuss the results of the 'Thermal Study' as conducted by the DIII-D fluid systems group. The following will be identified:

- Cooling loops and heat sources

- Coolant flows and heat loads

- System performance and recommendations

The DIII-D cooling system is composed of three heat removal pathways (Fig. 1). These pathways consist of different combinations of primary coolant loops and secondary coolant loops. The primary loop receives heat as it flows through a DIII-D component(s) and transfers this heat via an intermediate heat exchanger to the secondary cooling tower water loop for final heat rejection to the environment by evaporation of tower water. A programmable logic controller (PLC) collects thermal and flow data from the DIII-D components, the cooling water systems, and the cooling towers.

\section{DESCRIPTION AND PERFORMANCE OF EACH COOLING LOOP}

\section{A. Tower \#1 Cooling Loop}

The tower \#1 cooling system (CT\#1) handles much of the daily heat load of the DIII-D facility. The following systems require continuous heat removal to maintain specified temperatures: the electron cyclotron heating $(\mathrm{ECH})$ system,

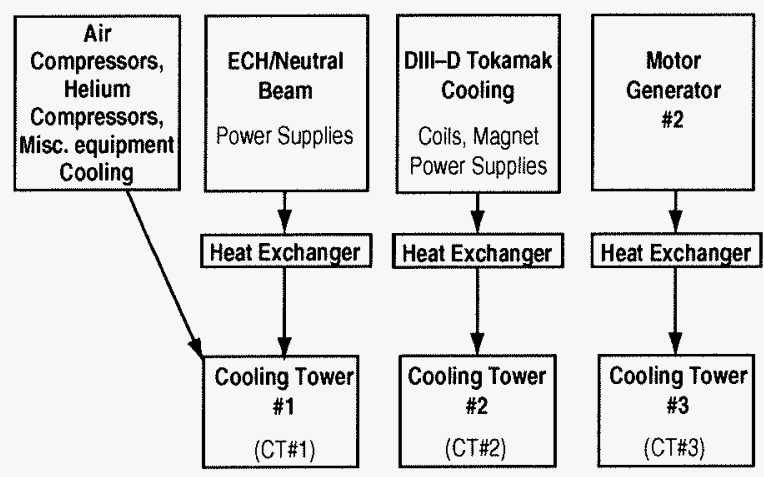

Fig. 1. DIII-D heat removal pathways.

the neutral beam ion source (NBIS) water cooling system, the helium compressor systems, and the various air-conditioning and process equipment systems. The ion cyclotron heating (ICH) system operates intermittently and the neutral beam closed loop heat exchanger only requires cooling if its main cooling system is off or fails. The ECH high pressure cooling water system (ECH-HP) removes heat from each of the six gyrotrons (plasma heating devices.) The ECH-HP consists of a primary cooling loop with de-ionized (DI) and deoxygenated (DO) water, which is maintained at a resistivity of $\geq 3 \mathrm{Mohm}-\mathrm{cm}$ and a dissolved oxygen level of $\leq 500 \mathrm{ppb}$ for voltage isolation from ground and decreased oxidation of the copper components, respectively. The low pressure cooling water system (LP) removes heat from the ECH, ICH and neutral beam (NB) power supplies using a primary cooling loop of DI water at a resistivity level of $\geq 3 \mathrm{Mohm}-\mathrm{cm}$. Both primary cooling loops transfer heat to the secondary CT\#1 loop via an intermediate plate-and-frame heat exchanger. The NB ion source (NBIS) water cooling system operates at a resistivity level between 10 and $2 \mathrm{Mohm}-\mathrm{cm}$ and a DO level of $\leq 10 \mathrm{ppb}$. Two Sullair helium compressors reject heat directly to the CT\#1. The air-conditioning (HVAC) and hot-dry-air compressors (for vacuum vessel baking) reject heat directly to the CT\#1 loop as well. Table I summarizes the present heat generating sources and cooling requirement for CT\#1.

\section{Cooling Tower Performance}

Throughout most of the year, the CT\#1 cooling system sufficiently cools the DIII-D facility; during the summer months, however, the heat removal performance is marginal due to higher wet bulb temperatures. Several times in the summer of 2003 the ECH-HP and LP cooling water temperatures climbed beyond the $33^{\circ} \mathrm{C}$ PLC alarm point limit. While Tokamak operations can continue above this alarm point, at $40^{\circ} \mathrm{C}$ the cooling systems will trip all ECH-HP cooling pumps and stop machine operations. Because of insufficient heat transfer across the intermediate heat exchangers to the secondary CT \#1 water, the ECH DI water storage tank experiences a net heat accumulation and hence 
Table I. PresentCT\# 1 Coolant Flows and Heat loads

\begin{tabular}{lcc}
\hline \multicolumn{1}{c}{ Sources } & $\begin{array}{c}\text { Flow } \\
\text { L/min } \\
\text { (gpm) }\end{array}$ & $\begin{array}{c}\text { Heat Load } \\
\text { MW }\end{array}$ \\
\hline Air conditioning \&hot air & 454 & 0.05 \\
Compressors & $(120)$ & \\
Helium compressors & 776 & 0.28 \\
& $(205)$ & \\
High pressure water HX & 1320 & 0.43 \\
for ECH gyrotrons & $(350)$ & \\
cooling & & \\
Low pressure water HX & 1140 & 0.39 \\
for ECH/neutral beam & $(300)$ & \\
power supplies cooling & & \\
NBIS cooling water heat & 284 & 0.05 \\
exchanger & $(75)$ & \\
Neutral beam closed & 379 & Emergency only \\
loop heat exchanger & $(100)$ & \\
ICH dummy loads & 379 & Intermittent on \\
& $(100)$ & demand only \\
TOTAL & 4730 & 1.20 \\
& $(1250)$ & \\
\hline
\end{tabular}

a temperature rise. Several factors contribute to this marginal performance of the CT\#1 loop:

- Summer ambient humidity limits cooling tower evaporation to the environment. The wet bulb temperature represents the theoretical lower limit of cooling tower outlet supply water temperature. Summer (July and August) ambient air and humidity charting indicates typical daily wet bulb temperature that changes from around $15.6^{\circ} \mathrm{C}\left(60^{\circ} \mathrm{F}\right)$ at night, to $22.2^{\circ} \mathrm{C}\left(72^{\circ} \mathrm{F}\right)$ at noon, and back to the $15.6^{\circ} \mathrm{C}\left(60^{\circ} \mathrm{F}\right)$ by night fall. The highest wet bulb recorded on site in August was around $24^{\circ} \mathrm{C}\left(75^{\circ} \mathrm{F}\right)$.

- Aging of the cooling tower and the system piping decrease CT\#1 system flow. Despite more frequent preventive maintenances $(\mathrm{PM})$ to the tower internals and repair to the fans, a significant amount of pieces of the cooling tower's epoxy liner and carbon steel piping corrosion products were still recovered from the tower basins during the August 2003 tower PM. Though the tower and pump strainers retained most of the large debris, debris $<3 \mathrm{~mm}\left(1 / 8^{\prime \prime}\right)$ still migrated downstream into the cooling tower water side of the equipment or settled out at low velocity points in the piping network.

- Sludge build up in the CT\#1 loop, as a result of two malfunctioning old chemical injection controllers and large quantities of airborne particulates, caused fouling in the plate-and-frame heat exchangers. Since the discovery of the malfunction from the biweekly tower water quality monitoring program, the old controllers were replaced by a new injection control system with significant improvement in sludge reduction.

2. Tower \#1 Cooling Loop Recommendation

a. Short Term Changes

Several actions were taken to keep CT\#1 temperatures at acceptable levels. A more aggressive cooling tower treatment program using a descaler with dispersants was implemented in mid-April 2003. The chemical treatment program has kept the tower nozzles, filters and heat exchangers relatively free from deposit or scaling, and the suspended sludge build up observed in the basin in August 2003 was substantially decreased. Also, to reduce heat load during July and August, the following guidelines for weekday DIII-D machine operations were observed: (1) when possible, three instead of four ECH-HP pumps were run (this requires water to unused $R F$ heating devices to be shut down), and (2) during machine operations both the main and standby pumps, in the cooling tower water side and in the ECH-HP \& LP DI water polishing loops, would be running to enhance heat transfer in the HXs.

\section{b. Longer Term Upgrades}

Estimated future heat loads and flow requirements are shown in Table II. To meet both current summer time and future CT\#1 heat load requirements, a system upgrade is necessary. To assist the development of future upgrades, a fluid flow model of the Cooling Tower \#1 piping system was made using "Pipe-Flo Pro" from Engineered Software. The model includes all pumps, piping, valves, and components that dictate system performance. Values of pressure drop through pipes and across components, and flows through each branch are calculated under a variety of operating conditions. Actual system flow and pressure measurements can be compared with simulated values for troubleshooting. Also, any number of "what if" scenarios can be analyzed quickly and the viability of cooling tower loop upgrades can be assessed based in part on their performance according to the model.

From both the process of creating the model and the model calculations, key conclusions have been

Table II. Future CT\#1 CoOlant Flows and Heat Loads Estimate

\begin{tabular}{lcc}
\hline \multicolumn{1}{c}{ Sources } & $\begin{array}{c}\text { Flow } \\
\text { L/min } \\
\text { (gpm) }\end{array}$ & $\begin{array}{c}\text { Heat Load } \\
\text { MW }\end{array}$ \\
\hline Air conditioning \&hot air & 454 & 0.05 \\
compressors & $(120)$ & \\
Helium compressors & 777 & 0.28 \\
& $(205)$ & \\
High pressure water HX & 1706 & 0.59 \\
for ECH gyrotrons & $(450)$ & \\
cooling & & \\
Low pressure water HX & 1895 & 0.53 \\
for ECH/neutral beam & $(500)$ & \\
power supplies cooling & & \\
NBIS cooling water heat & 284 & 0.147 \\
exchanger & $(75)$ & \\
Neutral beam closed & 379 & Emergency only \\
loop heat exchanger & $(100)$ & \\
ICH dummy loads & 379 & Intermittent on \\
& $(100)$ & demand only \\
TOTAL & 5875 & 1.45 \\
& $(1550)$ & \\
\hline
\end{tabular}


reached. First, to meet future heat rejection requirements of the ECH system, flow to the ECHHP heat exchanger will need to increase. The model indicates that a much higher overall cooling tower water flow will be necessary to meet the increased future demand and that the required system pressure under such flow conditions would be much higher. This information will guide future decisions regarding the $\mathrm{ECH}$ and LP portion of the cooling water system. Second, for more detailed analysis of system performance, a comprehensive set of actual system data is needed. Pressure, flow and temperature measurements in several critical areas will provide this data.

To resolve the ECH-HP and LP water systems heat transfer bottlenecks, a material-and-energy balance was performed for the entire CT\#1 loop, based on an estimate of anticipated heat loads and the associated flows for the next 3 to 5 years. Using the piping and instrumentation diagram (P\&ID) to guide the sizing of piping, instruments, heat exchangers and pumps capacity, a proposed layout of the upgrade is illustrated in Fig. 2. This includes:

- A new and higher capacity ECH plate-\&-frame heat exchanger

- Doubling ECH DI Polishing loop flow capacity with new re-circulating pumps

- $\quad$ Adding heat transfer surface (plates) to Low Pressure system heat exchanger

- Expanding piping sizes to minimize pressure loss in this portion of the CT\#1 cooling loop

- Combined DO/DI scrubbing loops with nitrogen blanketing for the storage tanks

\section{B. Tower \#2 Cooling Loop}

The tower \#2 cooling system (CT\#2) removes heat from the vacuum vessel, the neutral beam line, the DIII-D machine coils, and the machine coil power supplies. It consists of a primary and secondary loop similar to that of the ECH-HP water system, and intermediate plate-and-frame type HXs that isolate the DI water from the basin water of the CT \#2. The

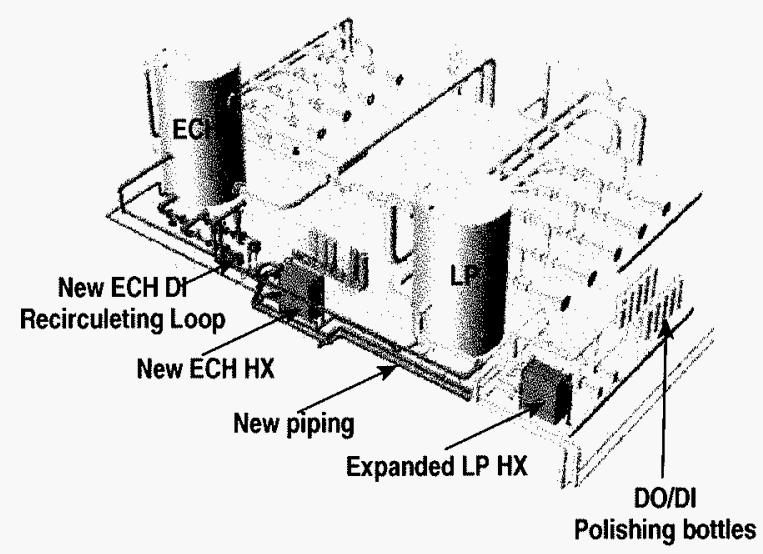

Fig. 2. Proposed layout of ECH high pressure and low pressure DI water systems to allow for future needs.

primary loop DIII-D water is maintained at a moderate DI water resistivity of $>0.04 \mathrm{Mohm}-\mathrm{cm}$ to minimize corrosion of the copper components and coils.

Tower \#2 cooling loop has to have enough heat removal capacity to handle the present DIII-D machine heat loads and pulse duration.

The heat generating sources, coolant flows, heat loads, and desired pulse durations are identified in the Table III. Although a portable monitoring device, equipped with rotameters and temperature sensor (RTD from Analog Device), and the PLC data analysis software permit evaluation of thermal transients in each type of magnetic coils, insufficient data have been taken to date to permit full analysis of system performance. In addition, more instrumentation is needed to study the impact of longer duration pulse $(10 \mathrm{~s})$ for each component of the DIII-D tokamak.

\section{Tower \#3 Cooling Loop}

To date the MG-2 Cooling System (CT \#3) has operated without any major problems. Tower $\# 3$ is the newest unit and is equipped with the modern induced draft fan design, and a stainless steel basin to eliminate corrosion. The heat removal capacity and efficiency is not limited in the near future.

TABLE III. CT\#2 COOLANT FLOWS AND HEAT LOADS

\begin{tabular}{lccccc}
\hline \multicolumn{1}{c}{ Sources } & $\begin{array}{c}\text { Flow } \\
\text { Lmin (gpm) }\end{array}$ & $\begin{array}{c}\text { Maximum Pulse } \\
\text { Duration }\end{array}$ & $\begin{array}{c}\text { Energy dissipated } \\
\text { for a 10 s pulse }\end{array}$ & $\begin{array}{c}\text { Average heat removal by CT\#2 in a 10 } \\
\text { min cooldown }\end{array}$ \\
\hline AWCS for vessel wall & & $\mathrm{s}$ & $\mathrm{MJ}$ & $\mathrm{MW}$ & Mbtu/hr \\
SPA & $1516(400)$ & 10 & 200 & 0.33 & 1.14 \\
PF (F)-coil power supplu & $455(120)$ & 10 & 60 & 0.10 & 0.34 \\
TF (B)-coil & $76(20)$ & & 42 & 0.07 & 0.24 \\
OH (E)-coil bus/ B-coil return bus & $3790(1000)$ & 10 & 742 & 1.24 & 4.22 \\
OH (E) \& PF (F) coil & $152(40)$ & 10 & 0.1 & 0.0002 & 0.0006 \\
RMW (I)-coil & $758(200)$ & 10 & 340 & 0.57 & 1.94 \\
Neutral beam closed loop & $227(60)$ & 10 & 0.5 & 0.001 & 0.003 \\
TF (B) power supply & $1516(400)$ & 5 & 70 & 0.12 & 0.40 \\
OH (E)-coil \& PF (F-T 1,2$)$ coil power & $910(240)$ & 10 & 312 & 0.52 & 1.78 \\
supplies & $948(250)$ & 10 & 446 & 0.74 & 2.54 \\
TOTAL & & & & & 3.7 \\
\hline
\end{tabular}




\section{CONCLUSION}

1. Throughout most of the year, the present Tower \#1 cooling system sufficiently cools the DIII-D facility. During the summer months, however, the heat removal performance is marginal. A few times under maximum operating conditions, i.e., 5 or 6 gyrotrons, all NBs and ICH running, CT\#1 loop could not maintain ECH-HP and LP DI water systems temperature to $<33^{\circ} \mathrm{C}$ in the late afternoon, due to marginal cooling tower \#1 water flow through ECH-HP and LP heat exchangers.

2. Tower \#2 cooling loop has enough heat removal capacity to handle the present DIII-D machine heat loads and pulse duration. There is no action at this time until more instrumentation is installed in the DIII-D cooling water circuit. More thermal transient data are needed to evaluate the impact of longer duration pulse for each component of the DIII-D tokamak.

3. Tower \#3 cooling loop's heat removal capacity and efficiency is not limited in the near future.

4. As a results of the thermal study, the following future work is recommended: a. Continue optimization of a cooling tower and heat exchanger system for Tower \#1 cooling loop.

b. Design and specify a new cooling tower system to eventually replace the aging CT \#1 and CT \#2 units.

c Use flow modeling to assess the new CT\#1 cooling system with the objective to increase cooling tower water flow to all users (including the options of upgrading Tower \#1 pump capacities).

d. Continue to assess DIII-D machine's TF \& PF-coils cooling efficiency. Recommend citric acid cleaning of cooling passages to increase flow and reduce cool down time, if cooling duration becomes unacceptable.

\section{ACKLOWLEDGMENT}

Work supported by U.S. Department of Energy under Contract No. DE-AC03-99ER54463.

\section{REFERENCES}

[1] System design description of DIII-D, Feb 1989, General Atomics Report GA-A1926. 